\title{
APPLICATION OF DIFFERENT HEAT TREATMENTS TO SPHEROIDAL GRAPHITE CAST IRON AND ITS EFFECT ON DAMPING AND MODE SHAPES
}

\begin{abstract}
Summary
In this study, damping and mode shapes were investigated after boriding and austempering the spheroidal graphite cast iron (SGCI). The samples were boronised and austempered at $900^{\circ} \mathrm{C}$ for 2 hours by employing the pack cementation method. The samples were cooled and tempered in a salt bath at $250^{\circ} \mathrm{C}$ and $375^{\circ} \mathrm{C}$ for 1 hour. Once the boriding and austempering processes were completed, the samples were cooled at room temperature and washed with plenty of water. The modal frequencies, damping ratios and mode shapes of these samples exposed to different heat treatments were acquired by using the experimental modal analysis (MA) method. The same characteristic features were acquired with the finite element method (FEM), and the results were compared. It was found that after the heat treatment the sample austempered at $250^{\circ} \mathrm{C}$ had a harder surface and a higher frequency than other samples.
\end{abstract}

Key words: $\quad$ spheroidal graphite cast iron, mode shapes, damping ratio

\section{Introduction}

Today, ferrous materials are commonly used in various industries. Spheroidal graphite cast iron (SGCI) is a newer material, and it serves as an alternative to steel in many applications. SGCI is suitable for heat treatment. It is a good material for engineering purposes, and its chemical properties (both its chemical composition and its internal structure (ferrite/pearlite)) can be changed with various heat treatments.

SGCI is a good quality material that has been produced in the last 20 years. It is highly stretchable and machinable, and it is corrosion-resistant. In addition, there are no limitations on SGCI workpiece dimensions or profiles [1]. Compared with other cast irons and cast steels, SGCI has superior properties, such as perfect castability, low melting point, heat treatment suitability, higher wearing resistance, better surface quality and high weight-tostrength ratio. It is superior to steel because of its graphite particles [2]. Today, SGCI is a type of material that can be applied in different industrial fields. The areas of use include mining and metallurgy, machining, agriculture, construction, chemistry and transportation. A number of studies have examined the properties of the materiel; some dynamic properties were determined with measurements of cantilever beam, plane frame and three-dimensional frame 
models with steel carrier systems, and they were compared with theoretical results [3]. The damping coefficient depends on the porosity of the material; that is, damping increases with porosity. The damping coefficient of porous magnesium is greater than that of non-porous magnesium. Mechanical damping in cellular metallic materials depends on structural factors and test conditions [4]. The results of an investigation into the natural frequencies of circular saws, (used in the metal industry) were checked using two different methods, the experimental and the numerical, and different mode shapes were acquired for circular saws [5]. The experimental modal analysis (MA) method was applied to diplexers. The situation of the system was observed at regular time intervals, and some modifications were determined. In their study, the authors tried to determine the dynamic properties of plane frames experimentally and theoretically. A model was created with the purpose of obtaining experimental measurements, and the results were compared with the theoretical results [6]. Five different slice profile samples were examined by three different methods. The second (2nd) and third (3rd) natural frequency values and mode shapes were found [7]. In another study, the vibration of a viaduct that was simply supported along the short side and the rectangular slab and had six squares supported from below by a longitudinal beam was examined [8]. Also, an abstract of an analytical model and its applications was presented for the dynamic modelling of a spindle, tool holder and tool system and for obtaining the tool nose frequency response function (FRF) [9]. In order to investigate behaviours of cutting tools before fracture occurs in machining, the authors analysed the conduct statically and dynamically using the finite element method (FEM) [10]. A closed-loop check design was created to determine the vibrational energy of smart structures for the vibration frequencies [11]. Natural frequencies, mode shapes and damping ratios of a roof system with a plane truss system were determined with the theoretical and operational MA methods [12]. The free and forced vibrational behaviours of laminated composite beams with different fibre orientations under dynamic load were also investigated [13]. Period and frequency investigations of the effect of the local error number on vibrational signals in the taller bearing geometry were performed and presented in[14]. It was determined that ensuring sufficient security of suspension bridges against dynamic loads (e.g. traffic, wind and earthquakes) depends on the proper determination of the dynamic loads (e.g. natural frequencies, mode shapes and damping ratio of the diplexer) [15]. The free vibrational frequencies of a rectangular plate with a distributed load were examined in [16], and the high frequency vibrations of thin plates were studied in [17].

In this study, five SGCI samples $182 \times 21.8 \times 17 \mathrm{~mm}^{3}$ in size underwent the boriding process and austempering heat treatments at $250{ }^{\circ} \mathrm{C}$ and $375{ }^{\circ} \mathrm{C}$. Then, the frequency periods, modal frequencies and damping ratios of each sample were acquired using both the experimental method and the FEM. In engineering design, resonance must be prevented in machine elements. The optimum design of a system is achieved by taking these parameters into account. Thus, finding the modal frequencies of a machine element is vital.

\section{Materials and Methods}

The SGDI samples were DIN GGG40 (182 × $21.8 \times 17 \mathrm{~mm}^{3}$ in size), and they were prepared for austempering and boronising heat treatment by turning on a CNC lathe.

\section{$2.1 \quad$ Boriding}

One of the methods used to enhance the surface quality is the boriding process. The boriding process turns the workpiece surface into a boride coat. In the boride coating the diffusion of boron atoms into the base metal takes place at high temperatures, so the boriding process is not a lining process. Diffusion of boron into different metals and alloys affects the 
composition of metallic borides, providing a surface resistant against extreme corrosion and erosion. Blocking the structures of borides with the base metal provides perfect coat adhesion. Metallic borides have a typical high contrast range of 1600-2100 HV [18]. The boriding process can be applied to well-cleaned surfaces of materials in the temperature range 700 $1000{ }^{\circ} \mathrm{C}$ in various platforms, such as solid, badigeon, fluid or gas, and in the $1-10$ time periods. With the recent technological advances, the new methods, such as plasma boriding and boriding into the fluid channel, are used in gas platforms in addition to the methods involving the thermochemical boriding process. Also, physical vapour decomposition (PVD), chemical vapour decomposition (CVD), and plasma aerosol and ion decomposition methods are used for the boriding process, and these methods are not thermochemical [19].

Firstly, one of the $182 \times 21.8 \times 17 \mathrm{~mm}^{3}$-sized SGCI samples was boronised at $900{ }^{\circ} \mathrm{C}$ for 2 hours, and then it was tempered at $375{ }^{\circ} \mathrm{C}$ for 1 hour in a salt bath. Finally, it was cooled at room temperature and washed by scrubbing. Then, another sample was boronised at $900{ }^{\circ} \mathrm{C}$ for 2 hours, tempered at $250{ }^{\circ} \mathrm{C}$ in a salt bath and washed by scrubbing after it was cooled at room temperature.

\subsection{Austempering}

Austempered SGDI is a type of cast iron obtained by the application of heat treatment on the SGDI. The material properties of the austempered SGCI can change according to the austempering parameters. Austempering heat treatment includes these steps: firstly, the material is heated at a suitable $\left(850-900{ }^{\circ} \mathrm{C}\right)$ austempering temperature, then, it was brought to the temperature of austempering with water $\left(250-450{ }^{\circ} \mathrm{C}\right)$, and finally, the material is kept there for 0.5-4 hours in order to complete its transformation at that temperature [20].

In this study, firstly, one of the $182 \times 21.8 \times 17 \mathrm{~mm}^{3}$-sized SGCI samples was austempered at $900{ }^{\circ} \mathrm{C}$ for 2 hours, and then it was tempered at $375{ }^{\circ} \mathrm{C}$ for 1 hour in a salt bath. Finally, it was cooled at room temperature and washed by scrubbing. Then, other samples were austempered at $900{ }^{\circ} \mathrm{C}$ for 2 hours, tempered at $250{ }^{\circ} \mathrm{C}$ in a salt bath and washed by scrubbing after it was cooled at room temperature.

\subsection{Vibration Analysis}

The experimental MA has been recently used for various studies. Theoretical and experimental studies have been examined to determine the vibrational characteristics of a structure through modal analysis. By applying the MA method the dynamic characteristics including the mode shape depending on the natural frequency, damping ratio and structural deformation of a structure can be obtained.

In addition, we need the MA method because a mathematical model is created while the systems are being analysed as theoretical. The experimental results are compared with the results of the mathematical model. Thus, the mathematical model is validated.

In the machine design, we need to define the resonance and know how the system will react when a force is used. Information about the mode shapes and vibration type of the system is helpful to the engineer during the system design. The analytical model may be verified by using the MA, and if the results are suitable for the physical model, this analytical model can be used for further changes and analyses. Also, it can help to determine dynamic movements and inherent weaknesses of each resonance frequency. In addition, it can help to remove all noise and vibration problems. Periodical vibration measurements are also necessary for looms and structures to operate within suitable and safe operating limits. 


\subsubsection{Experimental MA Measurement}

The experimental MA is a method that involves finding a response of the structure and system of a machine. Based on the response, it determines some of the dynamic properties. The system response can be measured as transposition, speed and acceleration.

In the experimental MA method, a force is applied to the system, and the reaction to this force is measured. A hammer is used to apply force, an accelerometer is used to measure the reaction of the system and a signal analyser is used to evaluate the results.

The Frequency Response Function (FRF) is the most important measurement for the modal analysis. In simple terms, this is the ratio of output response to input force. For this measurement, an FFT analyser or software that performs the same function should be used. Action and reaction functions are transformed to the frequency platform from the time platform using the Fast Fourier Transform (FFT).

The natural frequencies, mode shapes and damping ratios of the system are determined by using the frequency behaviour functions. An FRF occurs between each excitation point and measurement point. All data can be considered as the matrix of the FRF. Each line shows a response point, and each pillar shows an excitation point.

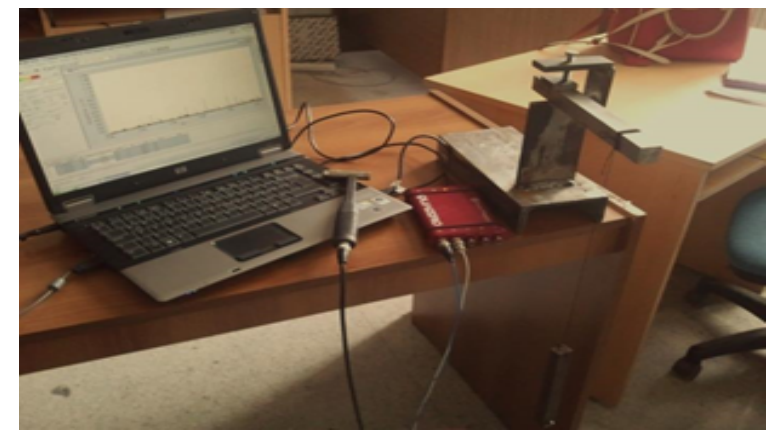

Fig. 1 Testing apparatus

The testing apparatus used in our study is shown in Fig. 1. The samples were hung longitudinally at a fixed point using a thin wire in order to measure with a high multi degreeof-freedom (DOF) system. The accelerometer was tied to three different points and was hit from these three different points. Thus, nine frequency graphics were acquired in total. Mode shapes and damping ratios were obtained from these frequency-magnitude graphics.

\section{Results and Discussion}

The $182 \times 21.8 \times 17 \mathrm{~mm}^{3}$-sized SGDI samples were boronised and austempered. The samples used in the experiment were austempered at $250{ }^{\circ} \mathrm{C}$ and $375{ }^{\circ} \mathrm{C}$ and boronised at $250{ }^{\circ} \mathrm{C}$ and $375{ }^{\circ} \mathrm{C}$.

Force was applied to the material with a hammer, and the response was measured with an accelerometer. There was a dynamometer at the end of the hammer that measured the force. Accelerometer and force were treated in a data collection card called FFT. First, the values of transformation were transformed from the time platform to the frequency platform and turned into a graphic with the help of the computer software.

The vertical axis made its $1 / \mathrm{kg}$ transformation in a vibration used in the comparison of the rate of acceleration [21]. There are frequencies on the azimuth axis. They indicate the resonance frequency values of the material. All modes of the material can be seen in the graphics. The peak points on the graphics show the material modes. The obtained graphics are presented in Figs. 2 and 3, in which the frequency values of the mode shapes are presented. The peak points in the graph are the modal frequency. 


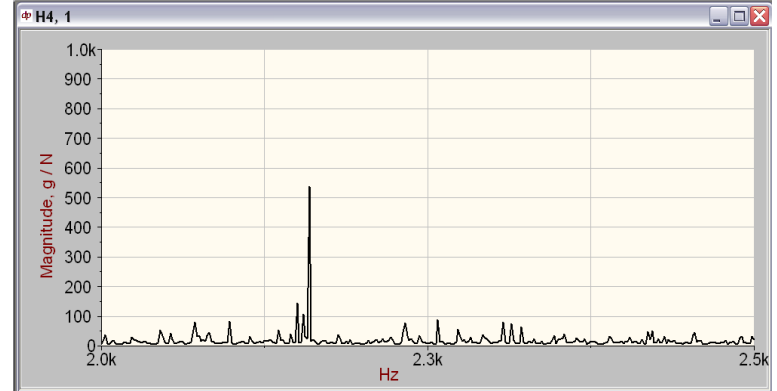

a) Modal frequency of raw material

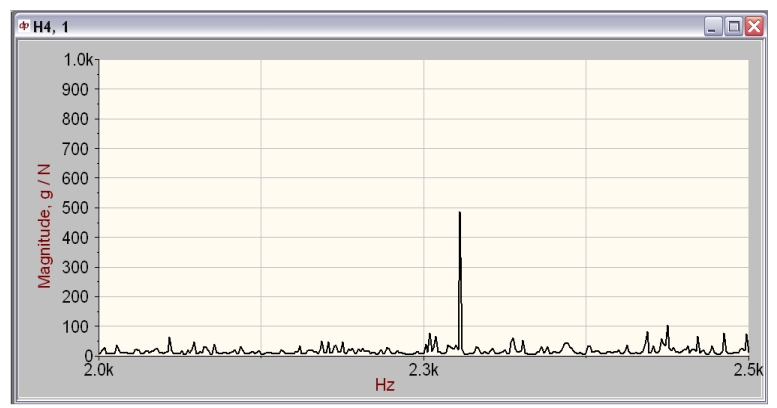

c) (375 Aust) Modal frequency of material

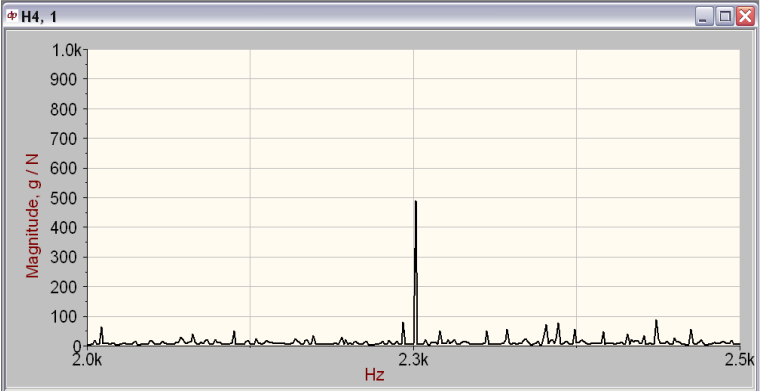

b) (250Bor) Modal frequency of material

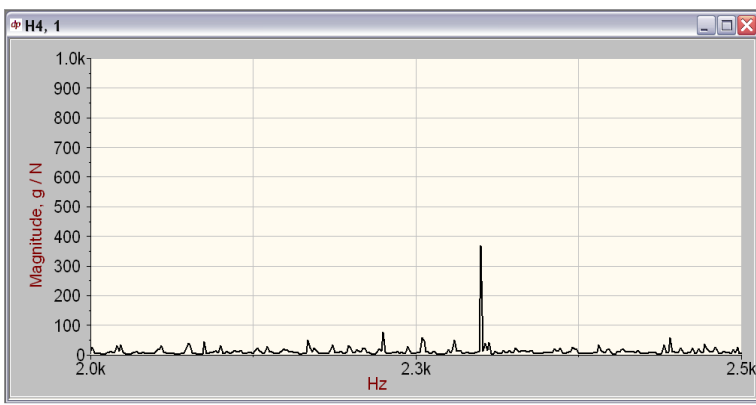

d) (250 Aust) Modal frequency of material

Fig. 2 Modal frequencies of different heat-treated materials $(2.0-2.5 \mathrm{kHz})$

The first modal frequencies of the material are important. The first modal frequencies of the four samples in the $2.0-2.5-\mathrm{kHz}$ periods are shown in the graphics in Fig. 2. The first modal frequency of the sample boronised at $375^{\circ} \mathrm{C}$ is shown in Fig. 3(a). If we compare the modal frequencies of the samples, we see that the lowest modal frequency is found in the raw material and that the highest modal frequency is found in the material austempered at $250{ }^{\circ} \mathrm{C}$.

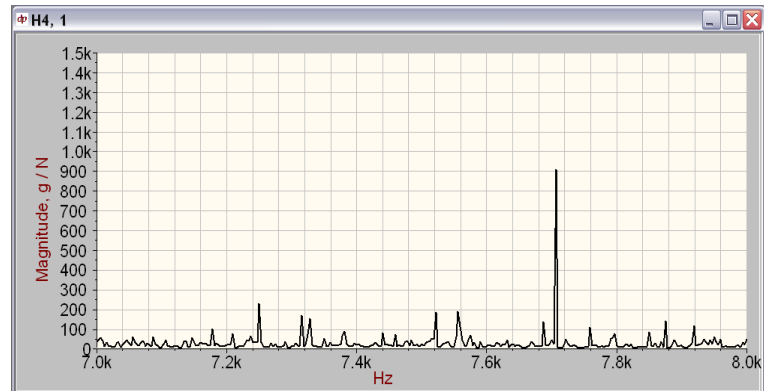

a) $2.0-2.5 \mathrm{kHz}$

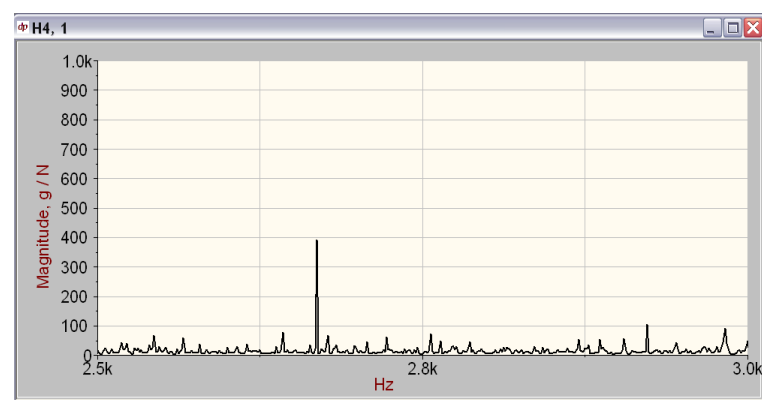

c) $8.0-9.0 \mathrm{kHz}$

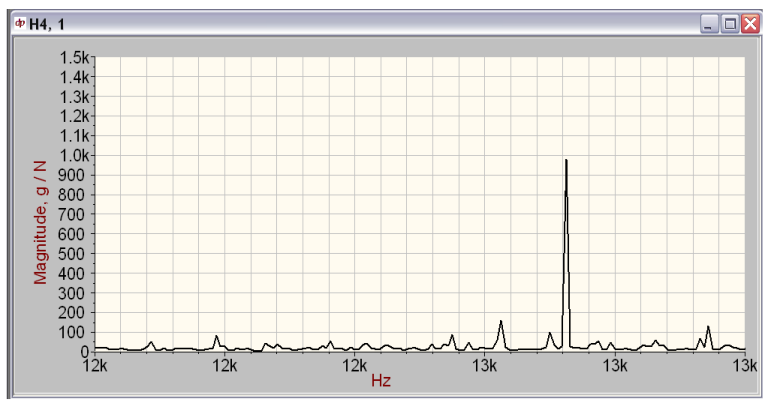

b) $6.0-7.0 \mathrm{kHz}$

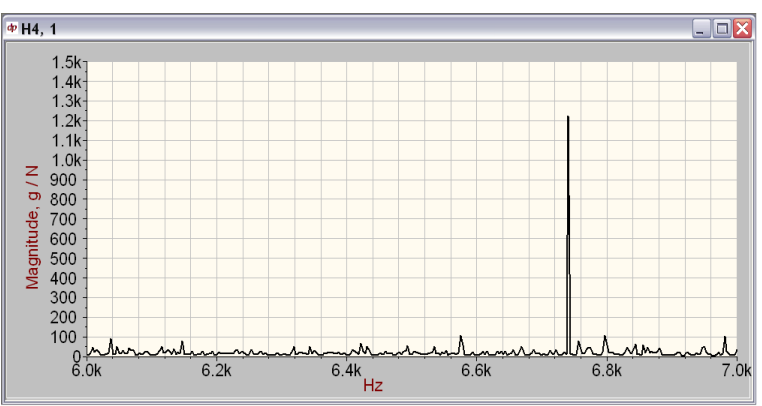

d) $12.0-13.0 \mathrm{kHz}$

Fig. 3 Modal frequencies of material boronised at $375^{\circ} \mathrm{C}$

The first eight modal frequency values of the raw and heat-treated materials are shown in Table 1. There are values with small amplitudes among them. Their frequency values are not taken. 
Table 1 Modal frequency values of raw and treated materials

\begin{tabular}{|c|c|c|c|c|c|}
\hline Material & Raw (x100) & 375B (x100) & 250B (x100) & 375AUST (x100) & 250AUST (x100) \\
\hline 1 & 2.18 & 2.28 & 2.30 & 2.32 & 2.34 \\
\hline 2 & 2.77 & 2.68 & 2.85 & 2.78 & 2.93 \\
\hline 3 & 3.40 & 3.18 & 3.08 & 3.39 & 3.26 \\
\hline 4 & 6.70 & 6.75 & 6.68 & 6.90 & 6.43 \\
\hline 5 & 7.65 & 7.71 & 7.44 & 7.92 & 7.81 \\
\hline 6 & 8.70 & 8.87 & 8.45 & 8.62 & 8.60 \\
\hline 7 & 11.79 & 11.74 & 11.72 & 11.95 & 11.63 \\
\hline 8 & 12.91 & 13.81 & 12.15 & 12.21 & 13.15 \\
\hline
\end{tabular}

The ABAQUS software was used for the analysis of the mode shapes of the samples. Using the ABAQUS software, the $182 \times 21.8 \times 17 \mathrm{~mm}^{3}$ dimensions of the geometrical shape of the sample were drawn. The mechanical properties of the material are shown in Table 3 . Free-free boundary conditions were analysed. A mesh model was created by using a finite element network made of a C3D8R element type with eight corners of a rectangular prismatic bar after entering the boundary conditions in the system. Fig. 4 shows the state of the finite element model mesh.

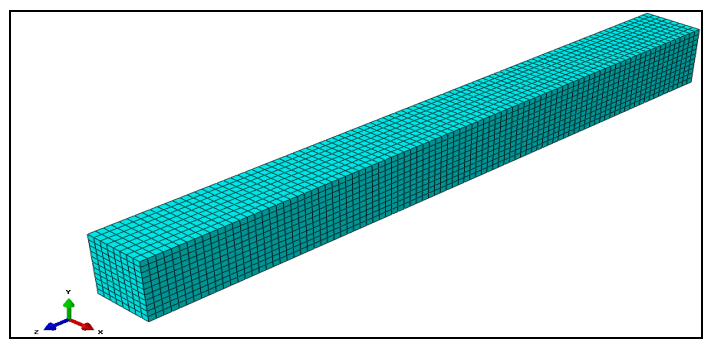

Fig. 4 FEM of sample mesh model

The model was made according to the free-free situation, and the first six modes of the calculation were acquired by considering the material properties. The mode shapes of the material that was not heat-treated are shown in Fig. $5(\mathrm{a}-\mathrm{d})$. The aspects of the modes are shown by choosing three axes.

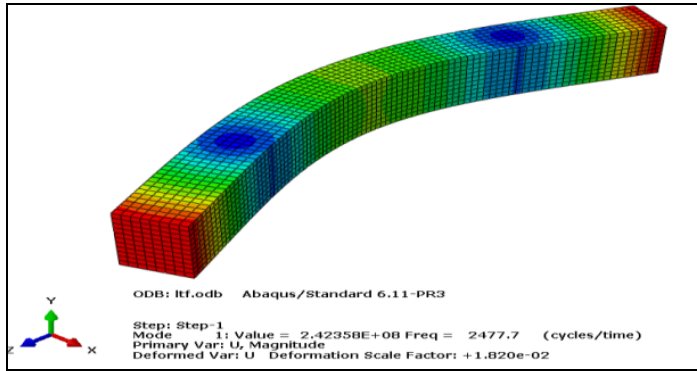

a) First mode

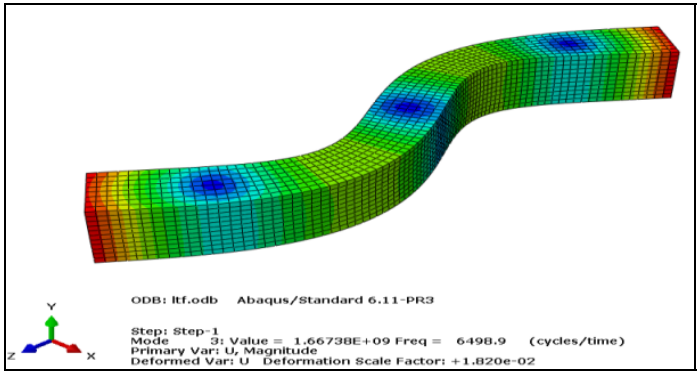

c) Third mode

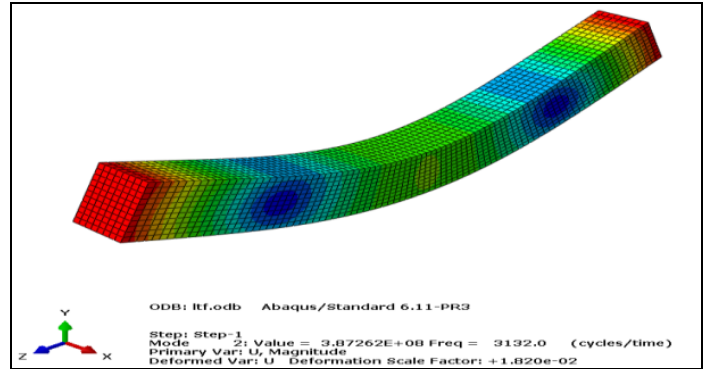

b) Second mode

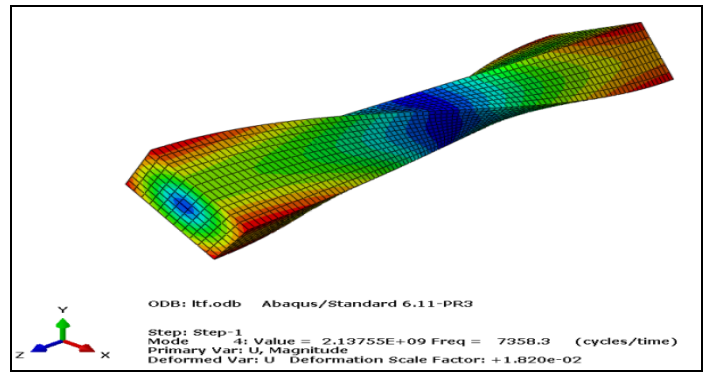

d) Fourth mode

Fig. 5 Mode shapes acquired by FEM 
The first mode of the material inclines towards the $X, Z$ plane in Fig. 5 (a). Since the samples were prismatic, they were examined relative to the $\mathrm{X}$-, $\mathrm{Y}$ - and $\mathrm{Z}$-axes. The second mode inclines towards the $\mathrm{Y}, \mathrm{Z}$ plane. The third mode inclines again towards the $\mathrm{X}, \mathrm{Z}$ plane. The fourth mode rotates on the $Z$-axis. Each mode shape has its own frequency value. This value begins to increase from the low frequency, and the last mode depends on the highest frequency. The modal frequency values acquired by the experimental method and the FEM are shown in Table 2. There are minor differences between the two values.

Table 2 Comparison of frequency values

\begin{tabular}{|c|c|c|c|}
\hline Mode & Frequency method (Raw samples) & Finite element method (Raw) & Difference \\
\hline 1 & 2.18 & 2.48 & 0.30 \\
\hline 2 & 2.77 & 3.13 & 0.36 \\
\hline 3 & 6.80 & 6.50 & 0.30 \\
\hline 4 & 7.60 & 7.36 & 0.24 \\
\hline
\end{tabular}

\section{Conclusion}

The surface hardness of the SGCI samples was increased by different heat treatments. The frequency response of the material was examined under the influence of external forces. Modal frequencies were acquired by modal testing. To compare the frequencies, the first six mode shapes and their frequencies were acquired by the FEM and in Table 2, the values are compared. In the study, we worked on the following samples of spheroidal graphite cast iron: not heat-treated, boronised at $375{ }^{\circ} \mathrm{C}$ and $250{ }^{\circ} \mathrm{C}$ and austempered at $375{ }^{\circ} \mathrm{C}$ and $250{ }^{\circ} \mathrm{C}$. Eight frequency values of all the material were acquired in the period between $2.0 \mathrm{kHz}$ and $13.0 \mathrm{kHz}$.

It was observed that the material enters the mode at high frequencies. According to the graphical values, in the case of the material that was not heat-treated the first mode occurred at $2.18 \mathrm{kHz}$. Second, in the case of the material boronised at $375{ }^{\circ} \mathrm{C}$ the first mode occurred at $2.28 \mathrm{kHz}$, and in the case of the material boronised at $250{ }^{\circ} \mathrm{C}$ the first mode occurred at $2.3 \mathrm{kHz}$. Finally, in the case of the sample austempered at $375^{\circ} \mathrm{C}$ the first mode occurred at $2.32 \mathrm{kHz}$, and in the case of the material austempered at $250{ }^{\circ} \mathrm{C}$ the first mode occurred at $2.34 \mathrm{kHz}$. Augmentation of the modal frequency depended on the surface hardness. The material had different geometric shapes at every modal frequency. An inflection occurred in the first modal frequency. The frequency values acquired by the MA and the FEM were compared. It was established that modal frequencies influence the surface flatness and the hardness of the material.

\section{REFERENCES}

[1] S. Karaman, C.S. Cetinarslan: Proof and tensile strength relationship of the spheroidal graphite cast irons have high elongation at break, International Iron \& Steel Symposium. (2012)

[2] A. Kacal, M. Gulesin, F. Melek: Evaluation of the cutting forces and surface roughness of GGG40 spherodial graphite cast irons in fine turning operations, Journal of Polytechnic, 11(2), 229-234. (2008).

[3] A. Bayraktar, T. Turker: Finite element modeling and experimental modal testing of steel structures. The 1st International Operational Modal Analysis Conference. (2005)

[4] L. Dahil, M.S. Baspinar, A. Karabulut: Damping effect of porous materials, Afyon Kocatepe University Journal of Science. 11(1), 21-26, (2011).

[5] I. Ucun, M. Colakoglu: Measurement and calculation of the natural vibration frequencies of the variedsection profile materials, Technology, 7(3), 433-435, (2004).

[6] C. Donmez, E. Karakan: 2009, Experimental modal analysis applications on bridges, IMO Technical Magazine, 318, 4851-4863, (2009). 
[7] A. Bayraktar, T. Turker: Finite element modeling and experimental modal testing of steel structures. First International Operational Modal Analysis Conference. (2005)

[8] I. Ucun, M. Colakoglu: Measurement and calculation of the natural vibration frequencies of the variedsection profile materials, Technology. 7(3), 433-435, (2004).

[9] A. Celık, K. Yuksek: Inflection vibrations of a straight and simply supported at both ends viaduct road, Turkish J. Eng. Env. Sci. 26, 193-200, (2002).

[10] A. Erturk et. all. Dynamic Analysis of the machining centre and determination in the process: applications of a new analytical model, Machine Design and Manufacture Magazine. (2006)

[11] Y. Isı: The analysis by the finite elements method of the pre-fracture behaviors of the cutting tool in machining, Magazine of Engineering and Architecture Faculty, Uludağ University. 9(2), (2004).

[12] T. Caliskan et. all: Active vibration control by the help of smart structures. 10th International Machine Theory Symposium. (2001)

[13] A. Bayraktar et. all: Operational modal analysis of the plane trussed systems, KTU Construction Engineering Department, Trabzon. (2006)

[14] A. Baltac1, A. Sarıkanat: Vibration analysis of the laminated composite beams have various fiber orientations by finite elements method, Dokuz Eylül University, Engineering Faculty, Science and Engineering Magazine. 8(3), 85-97, (2006).

[15] L. Magalca, H. Karagulle: Integration of the active vibration control of the mechanic vibrations by the finite elements method, 12. International Machine Theory Symposium, Erciyes University, 69, 75. (2005).

[16] H. Erdogan, et. all: Observation of the suspension bridges's vibrations with GSP TMMOB 12. Map Scientific and Technical Conference of Turkey. (2009)

[17] O. Kopmaz, S. Telli: Free vibration frequencies of the rectangular plate has distributed load, Pamukale University, Engineering Sciences Magazine. 7 (2), 215-222, (2001).

[18] A. Secgın: High Vibration Frequencies of the Thin Plates, Dokuz Eylül University, Graduat School Of Natural And Applied Sciences (2008)

[19] F. Gul, M. Cetın: Effect of the boriding process period on the adhesive corrosion behavior and frictional force of the spherodial graphite cast iron, Sixth International Advance Technologies Symposium. (2011)

[20] Y. Kayal1, Y. Yalcin: Effect of the austempering temperature on the micro-corrosion behavior of the austempered spherodial graphite cast iron, Fifth International Advance TechnologieSymposium. (2009)

[21] D. J. Ewıns: Modal Testing: Theory and Practice, John Wiley \& Sons, New York (1995) Claasguss, Tecnical İnformation, No:2

Submitted: $\quad 09.8 .2016$

Accepted: $\quad 28.02 .2017$
Lutfiye Dahil

Istanbul Aydın University, Faculty of Mechanical, Mechanical Engineering, Istanbul, Turkey.

Abdurrahman Karabulut Afyon Kocatepe University, Faculty of Technology, Mechanical Engineering, Afyonkarahisar, Turkey 